\title{
Retoques sobre $O$ juiz de paz da roça, de Martins Pena
} Refinishing considerations on Martins Pena's O juiz de paz da roça

Rafael Loureiro de Almeida ${ }^{1}$ 


\section{Resumo}

Recentes descobertas a respeito de uma das farsas mais icônicas do teatro brasileiro são expostas neste ensaio, a fim de propor novas reflexões acerca de sua elaboração. A partir da análise dos artigos de Darcy Damasceno, o principal pesquisador de Martins Pena, encontramos uma série de informações que nos permitem ampliar a compreensão sobre a peça. Além disso, ao consultar a coletânea de Martins Pena no acervo de Darcy Damasceno, encontramos algumas anotações que revelam suas últimas interpretações, o que inclui trechos antes desconhecidos.

Palavras-chave: Teatro brasileiro; Martins Pena; romantismo; farsa; Darcy Damasceno.

\section{Abstract}

In the light of recent discoveries concerning Martin Pena's play $O$ Juiz de paz da Roça, one of the most iconic farces of Brazilian theater, this paper proposes new reflections on its elaboration. Based on the analysis of the Darcy Damasceno articles, leading scholar of the work of Martins Pena, we found much information about the playwright, increasing our understanding of the farce's context. In addition, some notes in Damasceno's personal book reveal his latest interpretations of Martins Pena's comedies, which include previously unknown passages.

Keywords: Brazilian theater; Martins Pena; romanticism; farce; Darcy Damasceno.

ISSN: 1414.5731

E-ISSN: 2358.6958

\footnotetext{
${ }^{1}$ Doutorando em Letras Vernáculas pela Universidade Federal do Rio de Janeiro (UFRJ), Rio de Janeiro, RJ, Brasil. Conta com o apoio do Programa Nacional de Apoio à Pesquisa (PNAP) da Fundação Biblioteca Nacional para o estudo da vida e obra de Martins Pena. rafaeltomluz@gmail.com
} 
Entre as comédias de Martins Pena, O juiz de paz da roça foi a que mais fez sucesso, tanto na sua época quanto nos últimos tempos. Por conseguinte, foi a que mais teve edições, duas delas em vida do autor. As questões que envolvem sua elaboração são complexas, visto que o texto passou por diversas fases, dos manuscritos às coletâneas modernas. As publicações de 1842 e 1843 se tornaram as fontes primárias das edições posteriores, mas os estudos de Amália Costa e Darcy Damasceno fizeram vir a lume as versões manuscritas, ampliando o debate e o entendimento da consagrada comédia de costumes brasileiros. Com tantos estudos sobre a peça, poderiam também existir partes não divulgadas?

O principal trabalho de Darcy Damasceno para a obra de Martins Pena foi a organização de sua coletânea, na qual foram confrontados manuscritos e publicações do século XIX. Sua atuação, porém, não se limitou a esse feito. Se, por um lado, o trabalho gerou uma série de anotações que estruturaram artigos e ensaios futuros, por outro lado, mesmo a coletânea de 1956 foi alvo de alguns acertos críticos. Sabemos disso, pois tivemos acesso ao exemplar pessoal do pesquisador, no qual se encontram diversas notas que merecem divulgação e análise.

Por exemplo, Damasceno escreveu sobre a trajetória da guarda dos manuscritos no artigo $O$ teatro fantasma de Martins Pena. Segundo ele, a editora Garnier se interessou em publicar a obra completa de Martins Pena em 1898, por ocasião dos cinquenta anos da morte do dramaturgo. Na época, o repertório conhecido se resumia a sete comédias: $O$ juiz de paz da roça, A família e a festa da roça, O Judas em sábado de Aleluia, Os irmãos das almas, O diletante, Quem casa, quer casa, O caixeiro da taverna, $O$ noviço e Os dous ou $O$ inglês maquinista. Esse encolhimento estava para ser revertido com o interesse da editora, mas um incidente prolongou a situação por mais cinco décadas.

\footnotetext{
Quando se anunciou o propósito do editor, lembrou-se da existência, na Biblioteca Pública, de numerosos manuscritos inéditos, doados à instituição por parentes do comediógrafo. Estes, sabendo do intuito da casa Garnier, tentaram e finalmente conseguiram reaver o espólio dramático de Martins Pena. Foi uma pequena batalha de interesses e influências, que resultou na impossibilidade de serem divulgados os textos desconhecidos para a época (Damasceno, 2007, p. 244).
}

Posteriormente, os manuscritos foram devolvidos à Biblioteca Nacional e, por conseguinte, transferidos, na mudança de sede, da Rua da Lapa para a Avenida Rio Branco, sede atual. Contudo, devido a problemas de catalogação, permaneceram inacessíveis à pesquisa até a década de 1940, quando Wilson Louzada os encontrou. Darcy Damasceno, que iniciou seu trabalho na Divisão de Manuscritos em 1951, logo se interessou pela descoberta e, com a colaboração de Maria Filgueiras, organizou a publicação dos dramas e das comédias, agigantando a obra - antes restrita a sete comédias - para 26 títulos distribuídos em mais de mil páginas. Três anos depois, Damasceno preparava a edição dos Folhetins de Martins Pena, ao mesmo tempo em que finalizava seu livro de poesia Trigésimas, conforme afirmou ao jornalista José Condé, (Correio da Manhã, Rio de Janeiro, 14 jan. 1959, p. 12), mas as circunstâncias só permitiram a publicação dos Folhetins em 1965, assim como o livro de poemas teve de esperar até 1967. 
Quando tivemos acesso ao exemplar do acervo pessoal de Darcy, constatamos diversas anotações que indicam que ele prosseguiu o trabalho de pesquisa e, principalmente, que ele gostaria de fazer modificações caso houvesse uma nova edição da coletânea, o que não aconteceu. Na verdade, houve, sim, algumas republicações, mas o método de cópia de fotolitos não permitiu que as alterações fossem feitas.

Concentrando-nos apenas nas questões que envolvem a peça de estreia, O juiz de paz da roça, a primeira mudança está nas notas biográficas (1956, p. 8), alterando o provável ano de elaboração para 1837, desabonando o relato de José Francisco Viana sobre a peça ter sido escrita em 1833. A razão de Damasceno ter sido categórico nessa questão foram pesquisas suplementares, reveladas em dois artigos. 0 primeiro deles, $A$ elaboração de $O$ juiz de paz da roça, escrito durante a organização da coletânea, questiona as diferenças entre os manuscritos e a publicação de 1843, mas não contesta a data de elaboração; pelo contrário, antes afirma que "a informação recolhida de parente do autor por Luís Francisco da Veiga de que Martins Pena escrevera $O$ juiz de paz da roça em 1833 merece todo crédito, à falta de provas em contrário" (Damasceno, 2007, p. 224).

Contudo, esse seria apenas o ponto de partida para o entendimento sobre a elaboração da famosa comédia de Martins Pena e, de fato, Damasceno encontraria as provas que o convenceria a contrariar o relato do sobrinho do comediógrafo, como podemos atestar pelo artigo Curro, cosmoramas e museu. A descoberta foi feita de modo relativamente mais simples do que o método utilizado anteriormente, ou seja, o árduo trabalho de cotejar os manuscritos e tentar estabelecer datas por meio do tipo de papel ou da grafia utilizada (diferenciando os cortes calígrafos). Em vez disso, Damasceno se concentrou nos referentes da peça, especialmente naqueles que surgem no diálogo entre José e Aninha na segunda cena. Se a informação dos três teatros da Corte não é muito eficiente para precisar o tempo dramático, o curro de cavalinhos é bem útil, pois remete ao Circo Olímpico, que desembacara no Rio de Janeiro em setembro de 1837 com um grupo americano especialista em jogos acrobáticos com animais, entre eles o elefante Pizarro (primeiro da espécie a estar na cidade) e o macaco Major. Por conta desse fato, fica evidente que a elaboração da peça não poderia ser de um período anterior, ainda mais quando percebemos que as comédias de Martins Pena costumavam se ambientar na mesma época em que eram redigidas.

O objetivo do pesquisador era definir quantas redações foram feitas, quando foram feitas e, sobretudo, encontrar o tempo da ação dramática. Por isso, Darcy Damasceno prosseguiu com o novo método pelo restante da peça. $O$ resultado não apenas revelou que a elaboração de $O$ juiz de paz da roça só pode ter sido concluída a partir de 1837, mas também localizou precisamente o tempo da ação teatral.

Em socorro de nossa hipótese vem o próprio texto. Numa fala do manuscrito, que não foi aproveitada na versão impressa (cena XVI), a caipira Aninha monologa: "Deus permita que meu pai não se esqueça dos meus sapatos! A festa da Conceição é pra semana, e se for, quero ir de sapatos novos". Com esse dado, transforma-se a hipótese em certeza: ocorrendo a festa da Conceição a 8 de dezembro, a ação atualiza-se em fins de novembro, e tudo nos leva a crer que coincidissem aqui o tempo dramático (o da ação) e o tempo real (o da elaboração da peça) (Damasceno, 2007, pp. 248-9). 
Com obstinação, Damasceno encontrou as provas de que necessitava para descreditar a declaração do sobrinho de Martins Pena. Na verdade, a postura respeitosa do pesquisador se deve mais a uma particularidade metodológica do que à credibilidade do relato, que desde a publicação demonstrava não ser completamente fiável. A biografia de Luís Francisco da Veiga foi a primeira fonte bibliográfica a se tornar referência sobre a vida do autor e, com efeito, contém numerosas informações sobre o dramaturgo e se tornou um semeadouro às pesquisas posteriores. Porém, cabe-nos notar que existem falhas na acuidade de certos dados, e uma delas é a questão que envolve o ano de feitura da comédia.

Quando estudante do segundo ano da Aula de Comércio, escreveu, tendo apenas
18 anos (1833), a sua primeira comédia de costumes nacionais, O juiz de paz da
roça. Receoso, porém, de que o conhecimento dessa vocação literária pudesse
dificultar a realização de seu desejo de obter um emprego público (por serem in-
suficientes os rendimentos dos parcos bens que herdara de seus maiores), só fê-la
publicar e representar em 1841 ou 1842 (Veiga, 1877, p. 385).

Logo após o relato, o biógrafo emenda: "Publicar, pode ser; representar, não, segundo ficou dito irrefutavelmente" (1877, p. 385; grifo do autor), revelando a primeira das incertezas que rondam a declaração. A inconsistência acerca do ano de elaboração de O juiz de paz da roça não está explícita, mas é evidentemente questionável como o sobrinho de Martins Pena saberia o ano de elaboração da peça, visto que era criança quando conversou poucas vezes com o tio e, além disso, não sabia ao certo quais seriam as datas de representação e de publicação.

Usando novamente a biografia de Veiga, diz-se que Martins Pena teria frequentado, "durante algum tempo, a Academia de Belas Artes, onde adquiriu conhecimentos de arquitetura, estatuária e pintura, os quais distintamente revelou [...] nos escritos que publicou a respeito das exposições daquela Academia e sobre a cenografia" (Veiga, 1877, p. 378), o que se refere a outro período que o sobrinho não presenciou. Os livros com a relação dos alunos regularmente matriculados na Academia se encontram no arquivo do Museu D. João VI, na Escola de Belas Artes da UFRJ, que a sucedeu. Eles revelam que Martins Pena não foi aluno regular da instituição, visto que seu nome não consta em nenhuma das turmas. É possível que ele frequentasse o ambiente, e mesmo que tomasse algumas lições, mas, se isso ocorreu, foi de maneira informal, sem vínculo oficial. Como até hoje não foram encontradas provas mais palpáveis do que o relato da biografia, o mais provável é que se trate de um mito ou de um exagero.

No entanto, a parte mais plausível na declaração de Veiga parece que foi ignorada. Martins Pena não foi aluno regular da Academia de Belas Artes, mas escreveu sobre as exposições da instituição, assunto que será melhor detalhado em outro momento. As exposições na Academia de Belas Artes eram, na verdade, parte de um evento maior que celebrava o fim do ano letivo. As obras eram expostas, os alunos confraternizavam e, ao fim, entregavam-se prêmios aos melhores. A exposição em si se estendia pelos meses subsequentes para apreciação pública. Entre os mais interessantes artigos sobre o evento encontrados nessa pesquisa, sobressai-se o do jornal O Chronista de 13 de março de 1838, ou seja, do mesmo dia em que estreou Antônio José ou O poeta e a Inquisição. Na ocasião, o parlamentar francês Montalivet 
se posicionava de maneira favorável aos incentivos à arte, "principalmente da música e da comédia", e o jornalista se utiliza desse discurso para fazer analogias à situação das artes no Brasil e corroborar com a ideia de que a comédia é um bom caminho para a moralidade, um critério que, à época, era considerado primordial para a obra artística.

A comédia invade as divisas do tempo e do espaço, e faz-nos viver em todas as épocas e em todos os lugares, ora representando fielmente ao vivo as façanhas dos heróis, ou corrigindo os costumes que menos se amoldam ao progresso da civilização $(1838$, p. 4)

O artigo faz parte de um importante momento para a arte brasileira e, mesmo que não tenha sido escrito por Martins Pena, tem todos os ares de ter sido escrito para ele. É interessantemente suspeito que o artigo comente sobre uma exposição da Academia de Belas Artes, porém valorizando a música e a comédia (que não eram oficialmente ensinadas ali), e o fato de ser o dia da representação de $O$ poeta e a Inquisição (considerada a primeira peça do Romantismo brasileiro) é bastante significativo. Em primeiro lugar, é improvável que os amigos ou admiradores de Gonçalves de Magalhães (como, por exemplo, Manuel de Araújo Porto-Alegre) tenham redigido o artigo, que, além de não o mencionar, ainda valoriza o gênero da comédia, indo contra o estilo da peça que estrearia àquela noite. Além disso, a opinião do artigo diverge das posições da revista Nitheroy, em que a comédia é mencionada apenas uma vez e de passagem, em "Literatura grega e romana", por João Manuel Pereira da Silva, durante sua abordagem sobre a evolução das artes na Roma Antiga.

\footnotetext{
A musa trágica nunca foi conhecida em Roma. [...] Nas repúblicas altivas, e nas monarquias absolutas, não é permitido que se honre, ou se avilte, o que de alguma sorte constitui sua grandeza pública. Ora, o Teatro é um tribunal terrível, onde os homens, cujos nomes traçam a história com caracteres imortais, devem aparecer com suas virtudes, e crimes, revezes e felicidades, para receber a glória ou o opróbio; portanto, o poeta não pode representar diante do povo fatos de sua história que, só com a lembrança de ter sido seus, não quer que se lhe toque, ou diante de Reis, os grandes crimes políticos que não podiam ser cometidos senão pela vontade ou influência dos antepassados monarcas. A comédia, cuja missão é de zombar, e de criticar para moralizar, não foi mais feliz do que o drama, foilhe mister recorrer a vestes e nomes de nações estrangeiras para poder pintar $\mathrm{o}$ rídiculo dos romanos (Silva, 1836, pp. 227-8).
}

Com efeito, as ideias dos redatores da revista Nitheroy estavam relacionadas com as poéticas da Antiguidade Clássica, propondo avanços tímidos, enquanto que o artigo de 13 de março de 1838 incentivava a produção da vanguarda, no caso, o Romantismo em suas mais variadas formas. João Manuel Pereira da Silva redigiria diversos contos e novelas nos anos seguintes, inclusive em O Chronista, mas seu estilo é de uma constante seriedade, evitando-se margens de riso (uma notável exceção seria o conto "O banho russo").

De qualquer modo, enquanto o Teatro Constitucional Fluminense se preparava para uma noite emblemática da cena brasileira, que repercutiria em numerosos elogios para Gonçalves de Magalhães e João Caetano, um pequeno artigo sobre a Academia de Belas Artes incentivava a criação de comédias, e é certo que tenha sido lido por Martins Pena, que estrearia a sua primeira farsa sete meses depois. 
Temos um novo fato externo a acrescentar sobre a elaboração de $O$ juiz de paz da roça, que é o de Martins Pena ter vivido uma longa disputa judicial pela herança de seu avô materno, José Antônio da Costa Guimarães, iniciada alguns anos antes da estreia da comédia e só terminada anos depois. Desde a morte de Francisca de Paula, mãe de Martins Pena, em 1825, o avô se encarregou de tutelar os netos e os bens da filha falecida, que, por sua vez, havia herdado os bens do primeiro cônjuge.

A mãe de Martins Pena faleceu devido a complicações do pós-parto da única filha que teve com o segundo esposo, o capitão Antônio Maria da Silva Torres, natural da Bahia. Este teve sérios desentendimentos com o sogro, pois o capitão se inclinou a disputar judicialmente todos os bens de Francisca de Paula, o que incluiria a parte pertencente aos filhos do primeiro casamento. $O$ avô conseguiu, apesar das reclamações em contrário, manter os poucos bens em juízo, assim como acolheu os órfãos até a sua morte, em janeiro de 1836.

Contudo, em meados de 1836, os dois irmãos ainda não estavam de posse das heranças do pai ou do avô, pois tudo estaria sendo inventariado pelo tio e disputado entre ele, credores do avô, outros familiares e Antônio Maria, novamente requerendo uma parte para Joana Torres, a segunda filha de Francisca de Paula. Nessa ocasião, até Martins Pena agiria oficialmente, tendo seu nome impresso pela primeira vez (Correio Official, Rio de Janeiro, 20 jul. 1836, p. 67) se referindo à leitura de seu requerimento na sessão de 22 de abril da Câmara Municipal. Martins Pena era frequentador da Biblioteca Nacional e, a partir de dezembro de 1836, consultou o Correio Official constantemente até abril do ano seguinte, um comportamento e tipo de leitura que diferem de todos os seus registros de consulta anteriores e, logicamente, estariam relacionados a questões jurídicas.

O caso se prolongou por bastante tempo, com diversos requerimentos para troca de juízes considerados suspeitos, impedimentos, recusas de nomeação, pedidos de apelação, ação de libelo de nulidades, enfim, uma série de recursos que fizeram o processo passar por todas as esferas do judiciário. O caso chegaria ao Supremo Tribunal, que se decidiria, em 6 de julho de 1838, a favor do tio de Martins Pena, "por haver injustiça notória no Acórdão de que se recorre" (Correio Official, 12 out. 1838, p. 2).

Frente à derrota, Antônio Maria voltaria aos jornais, em nome de sua filha, com um anúncio "contra o inaudito procedimento do [...] juiz nomeado para os inventários" (Jornal do Commercio, Rio de Janeiro, 28 fev. 1839, p. 8). O anúncio, longe de ser apenas mais uma reclamação sobre o processo judicial, é altamente suspeito frente aos acontecimentos da véspera. A partilha do inventário foi litigiosa e demorada, mas ficou pronta e, no dia 27 de fevereiro, os autos foram enviados para receber o selo oficial. É nesse ponto que, misteriosamente, o encarregado pelo serviço desaparece junto com os documentos. A primeira denúncia pública sobre o ocorrido surge no Despertador (Rio de Janeiro).

Em resposta ao anúncio e célebre protesto de D. Joana, filha do Sr. Antônio Maria da Silva Torres, a qual não pôde levar a paciência que lhe escape das unhas a presa que tão ilegalmente empolgou, isto é, a administração da herança do falecido José Antônio da Costa Guimarães, temos a ponderar ao público ilustrado que é mister requinte de perversidade, para atribuir a sinistras intenções o fato de um juiz deixar de fazer uma audiência, como se isso não sucedesse frequentemente com todos; e muito mais quando a partilha já está feita e assinada por partidores e juiz, e é indiferente que seja julgada por Pedro ou por Paulo. 
Saiba agora o público até que excessos a chicana tem chegado: no dia 27 foram os autos do inventário mandados selar, entregando-os para isso o escrivão Castro ao seu fiel, pelo meio-dia; e (caso raro!) desapareceu o fiel com os autos. Quem seria o motor disto? O público ajuíze: ficará um tal fiel sem castigo? Continuará ele a merecer a confiança do Sr. Castro? Não é de esperar. (1ำ mar. 1839, p. 4)

O Jornal do Commercio confirmaria a denúncia no dia seguinte com o anúncio do escrivão Castro, em que declara o desaparecimento de seu fiel de cartório Manoel Antônio da Fonte e pede: "com muito obséquio, a toda e qualquer pessoa que tiver notícia do mesmo fiel, queira fazer aviso no seu cartório, na Rua do Rosário" (1839, p. 4). Essa não seria a única repercussão do caso. José Feliciano da Cunha (um defensor de Antônio Maria) se mostraria bastante ofendido com a publicação do Despertador, redigindo uma longa réplica, na qual reprova o tom satírico do comunicado.

Embora não tenha sido revelado publicamente quem escreveu a nota, seria bem válido cogitar que Martins Pena tenha sido o autor, porque o assunto lhe dizia respeito e a redação é bastante condizente com o seu linguajar. Nesse ponto, ele já teria iniciado a atuação literária, tendo publicado contos nos jornais e sido representado nos palcos com O juiz de paz da roça. Apesar de a comédia não lidar com casos de partilha (caso mais complexo do que a disputa por um leitão), tem muitas similaridades com as notícias e experiências que o dramaturgo teria lido e vivenciado à época. Sabe-se que a comédia teve alguns acréscimos desde a versão manuscrita existente - datada de 1837 - até a última publicação em vida do autor (1843), e um deles é o trecho a seguir:

\footnotetext{
José da Silva - Eu vou queixar-me ao presidente.

Juiz - Pois vá, que eu tomarei a apelação.

José da Silva - E eu embargo.

Juiz - Embargue ou não embargue, embargue com trezentos mil diabos, que eu não concederei a revista no auto do processo!

José da Silva - Eu lhe mostrarei, deixe estar.

Juiz - Sr. Escrivão, não dê anistia a este rebelde, e mande-o agarrar para soldado (Pena, 1956, p. 38, Cena XI).
}

Nesse caso, a origem da cena se encontra num manuscrito avulso, que foi escrito em período posterior aos outros manuscritos da mesma peça, contendo: "carta ao juiz de paz, requerimento e pleito sobre o leitão e requerimento para citar-se a Assembleia" (Damasceno, 2007, p. 230). Alterações como essa certamente contaram com as últimas experiências do processo de inventário. Afinal, a escrita de $O$ juiz de paz da roça coincinde com a regularidade de leitura do Correio Official e estreia durante o longo litígio mencionado. Logo, a primeira versão da comédia ainda seria acrescida com alguns trechos, da mesma forma que o processo da partilha ainda passaria por momentos mais absurdos.

Os esforços de pesquisa demostraram que a peça, ao menos como primeira versão finalizada, não poderia ser de antes de 1837. Além disso, de acordo com o caso do julgamento da partilha, apesar de os últimos pormenores só terem sido concluídos em 1ำ de março de 1841 (em consonância com o que foi relatado), os agravantes do litígio só se iniciaram em 1836. Por outro lado, encontramos dois curiosos registros 
satirizando juízes de paz da roça, ambos divulgados antes de 1837. O primeiro é o poema "Ladainha de Todos os Santos", publicado em O Noticiador (Vila do Rio Grande do Sul, 12 out. 1834, p. 4), no qual há duas quadrinhas que merecem destaque.

\author{
De repimpado Escrivão, \\ Que as Partes demoram os Pleitos, \\ E quer seja pró, quer contra, \\ Acha em tudo certos jeitos.... \\ Libera nós, Domine. \\ De Juiz de Paz da roça, \\ Que, quando quer despachar, \\ Vai perguntar ao vizinho \\ Que despacho há-de dar: \\ Libera nós, Domine!!!!
}

O poema satírico tem o pioneirismo de ser uma das primeiras publicações brasileiras com a expressão "juiz de paz da roça". Embora as críticas às atitudes dos juízes fossem constantes à época e a expressão já tivesse sido cunhada em outros meios não literários, a intertextualidade entre a quadrinha do juiz de paz da roça e a explicação dada pelo Juiz ao Escrivão na cena XXI é suficiente para desconfiar de que não se trata de uma coincidência.

Escrivão - Pois Vossa Senhoria não sabe despachar?

Juiz - Eu? Ora, essa é boa! Eu entendo cá disso? Ainda quando é algum caso de umbigada, passe; mas casos sérios, é outra coisa. Eu lhe conto o que me ia acontecendo um dia. Um meu amigo me aconselhou que, todas as vezes que eu não soubesse dar um despacho, que desse o seguinte: "Não tem lugar" (Pena, 1956, p. 42).

O segundo registro encontrado acerca dos juízes de paz da roça está na coluna "Obras publicadas" do Diário do Rio de Janeiro (Rio de Janeiro) de 6 de fevereiro de 1836. Trata-se do primeiro anúncio de uma folhinha denominada Correio de Mentiras.

\footnotetext{
Saiu à luz, e acha-se à venda o $1^{\circ} \mathrm{n}$. da interessante folha Correio de Mentiras, contendo um longo artigo em que fala sobre os Ministros de Estado, Ditadores, Escrivães, Escreventes, Desembargadores, Advogados, e finaliza com Meirinhos e Cômicos, aonde os Músicos também não são esquecidos, e os Malsins sem ordenado: e segue a história do juiz de paz da roça, que recrutava com uma matilha de cães, e por fim fica logrado; traz a questão entre dois grandes facultativos sobre o estabelecimento de um cemitério; e o desafio do amante apunhalado, com o Lucas. Preço 80 rs. nas lojas do costume (p. 2).
}

A leitura desse texto deve ser feita com alguma cautela. É preciso ponderar, principalmente, que se trata de um anúncio e, por isso, poderia estar prometendo mais do que, de fato, teria a oferecer. Pelo preço da folhinha, a obra seria composta de, no máximo, quatro páginas, nas quais o "longo artigo" ocuparia o maior espaço, e as outras matérias não teriam mais do que uma página, contendo, cada uma, entre duas e quatro colunas de texto. É muito improvável que alguma cópia esteja preservada; 
logo, as únicas referências encontradas a respeito dessa pequena publicação são os poucos anúncios no Diário do Rio de Janeiro, que mencionam apenas o primeiro número, indicando que a folhinha tenha sido um projeto avulso e descontinuado.

O segundo anúncio, que justifica um pequeno atraso na publicação, é pouco diferente do primeiro. Porém, dessa vez, cita que a folhinha tinha por intuito mostrar "o grau elevado a que se acha a classe dos mentirosos; [...] depois segue-se a agradável história de um juiz de paz da roça, que recrutava com uma matilha de cães, e da logração final que leva" (9 fev. 1836, p. 2). Entretanto, ainda que fosse possível encontrar tão rara publicação, além de serem remotas as chances de o texto ter sido escrito por Martins Pena, não seria a elaboração da peça, mas a de um texto precursor, uma narrativa em que o juiz de paz persegue recrutas para enviar à guerra. $O$ entrecho não deixa de ter algumas semelhanças com o da comédia de Martins Pena, visto que o conflito se dá exatamente por conta de José ser recrutado para lutar no Rio Grande do Sul, um procedimento que estava em voga, sendo bastante comentado e, por conseguinte, estendendo-se à ficção. Outra pequena semelhança seria o uso de cães, embora os que aparecem na comédia não sejam do juiz de paz, mas de Manuel João, e que "não mordem" (Pena, 1956, p. 33). Portanto, ainda que pudessem existir fortes relações intertextuais entre a história e a comédia, a elaboração da peça só poderia acontecer em fins de 1837, pelas razões que Damasceno levantou em sua pesquisa.

Uma vez esclarecido que o contexto que envolve a elaboração de $O$ juiz de paz da roça é complexo, voltemos à tese proposta por Damasceno no que se refere às alterações do texto. No primeiro artigo, sem desconsiderar a data mencionada pelo sobrinho do dramaturgo, Damasceno menciona três primeiras etapas de alterações do texto. A primeira seria o manuscrito de 1837, considerado como cópia por ter o texto "limpo e continuado - ao contrário do que se dá com os rascunhos de outras comédias" (Damasceno In: Pena, 1956, p. 8), mas é preciso ter em mente que, mesmo sendo uma cópia, trata-se da compilação da peça que subsiste e que recebe novas alterações, tornando-se, portanto, o principal manuscrito existente. As outras duas etapas se referem a acréscimos nas cenas IX e XI, todas referentes aos casos do juiz, sendo que a cena IX, na qual se encena a audiência do juiz aos reclamantes, ganha dois casos novos e três personagens para representá-los, entre outros ajustes. Em outras palavras, a cena, muito significativa para a farsa, ainda não estava pronta em 1837, que contava apenas com duas contendas, sendo preciso mais dois tratamentos para ficar semelhante ao texto da primeira publicação.

Contudo, somando-se esses manuscritos, ainda ficariam faltando alguns elementos que aparecem na primeira publicação, sinal de que os acréscimos citados não foram os últimos. As diferenças não são muitas, porém atestam mais uma etapa da elaboração do texto, na qual foram feitos pequenos mas significativos retoques e acréscimos de diálogo. Damasceno trata dessa questão, embora não seja o assunto principal, no ensaio que identificou o tempo de ação da peça. Durante a procura pelos referentes que o ajudaram a situar a peça, Damasceno percebeu que a maioria dos acréscimos se dá em final de fala, levando-o à conclusão de que alguns deles foram feitos "no momento de serem feitas as cópias para a gente do teatro" (Damasceno, 2007, p. 250). Isso vale para alguns dos referentes, como o macaco Major, mas 
também se aplicaria a outros trechos da peça. Mesmo a cena IX recebe mais acréscimos em fim de fala, como na desculpa do Juiz para não assistir à demarcação do sítio: "requeira ao suplente, que é meu compadre Pantaleão" (Pena, 1956, p. 36; grifo nosso), nome que não está no manuscrito avulso. Nossa opinião é que tais acréscimos são aproveitamentos dos cacos de seus primeiros atores, que tiveram a liberdade de fazer os últimos ajustes às falas, e os melhores resultados acabaram revertidos ao texto final.

Uma das falas que foram modificadas é a de Aninha só ao procênio, no fim da segunda cena: "Como é bonita a Corte! [...] Teatros, mágicas, cavalos que dançam, cabeças com dous cabritos, macaco major... Quanta cousa!" (Pena, 1956, p. 31). Chama-se atenção para o chimpanzé, mas pouco se fala da modificação de "cabritos com duas cabeças", presente no manuscrito, para "cabeças com dous cabritos", na versão publicada. Pressupõe-se que não seja um descuido, porque, pelo contrário, é fácil conceber que essa inversão tenha sido proposital, ênfase na ideia de Aninha ser ingênua e estar sendo ludibriada. A modificação, posterior à redação original, copiada e emendada, tem todos os ares de ter sido feita em coautoria durante os ensaios e primeiras representações, tendo sido experimentada em cena, aprovada pelo público e revertida ao texto.

Além dessas alterações já acessíveis aos estudiosos, encontramos mais algumas notas no exemplar do acervo pessoal de Darcy Damasceno sobre $O$ juiz de paz da roça, pequenos arranjos que poderão ser úteis a futuras publicações da comédia. Pelo que pôde ser constatado, elas se referem a pequenas emendas no manuscrito de 1837 e no segundo dos manuscritos avulsos que não foram incorporadas à edição de 1956.

Nas notas da cena IX, há uma pequena emenda, o acréscimo da expressão “Deus louvado" na carta de Manuel André de Sapiruruca, cuja origem é um manuscrito avulso. Assim, no manuscrito, o início da carta é o seguinte: "Muito me alegro de dizer a V. S. que a minha é boa ao fazer desta Deus louvado, e que a mesma fortuna desejo a $\mathrm{V}$. S." (Pena, 1956, p. 50; grifo nosso). A alteração, embora pequena, esclarece o sentido original de humor que Martins Pena tentou dar ao início da carta, mesmo que, por razões desconhecidas, o trecho tenha sido suprimido na edição de 1843.

As outras alterações se referem à pequena cena XVI e são mais significativas que a anterior. Na publicação de 1956, a pequena cena mereceu cinco notas de Damasceno, como podem ser conferidas a seguir:

Casa $^{1}$ de Manuel João. Entram Maria Rosa e Aninha com um samborá2 na mão.

Maria Rosa - Estou moída! Já mexi dois alqueires de farinha.3

Aninha - Minha mãe, aqui está o café. 4

Maria Rosa - Bota aí.5 Aonde estará aquele maldito negro?

A segunda nota se deve à preservação da grafia utilizada para "samburá" (cesto de cipó), e as outras quatro se devem às diferenças no cotejo com o manuscrito de 1837. A nota número 5 se refere à exclusão da fala de Aninha, na qual menciona querer ir de sapatos novos à festa da Conceição. Uma pequena fala, mas que foi crucial para o pesquisador definir o ano de composição da comédia. 
Junto à terceira nota, que menciona a primeira fala de Maria Rosa no manuscrito: "Estou que não posso comigo! Já mexi meio alqueire de farinha, por hoje basta" (Pena, 1956, p. 53), há um grifo no exemplar pessoal de Damasceno sobre as palavras "por hoje basta" seguido pelo acréscimo: "Sobre estas últimas palavras, a expressão, lançada mais tarde e que seria a válida: e fiz um balaio de bijus" (grifo do autor). Vale ressaltar que esse trecho não consta em nenhuma edição consultada.

Além disso, Damasceno acrescentou uma sexta nota ao fim da cena, em que diz: "No manuscrito, entre parênteses, abaixo da última palavra, a indicação, posta posteriormente - (Mais.) - O intuito seria de aumentar a cena, o que não se deu" (grifo do autor). Apesar de parecer estranho Damasceno não mencionar nenhuma dessas notas em seus ensaios, a quantidade de anotações do pesquisador nos permite atestar que não é raro encontrar informações não divulgadas entre elas. Damasceno tinha o sábio costume de não divulgar suas hipóteses enquanto elas não estivessem muito bem averiguadas, e algumas delas ficaram incompletas no meio do processo.

Contudo, não deixa de ser impressionante encontrar informações inéditas acerca da mais citada comédia de Martins Pena, mesmo sendo atribuídas a seu principal pesquisador. É como se um instante da tradição teatral brasileira se revelasse irreverentemente sobre nós, a elaboração de uma cena incompleta entre mãe e filha cuidando dos afazeres da roça sem a presença do cabeça da família.

Todas essas pequenas descobertas a respeito da elaboração da mais icônica farsa de Martins Pena devem ser vistas como uma pequena mas contundente prova de que o dramaturgo merece o seu destaque no elenco de intelectuais da primeira geração do Romantismo, assim como seus textos são valiosos para ilustrar o nascedouro da tradição teatral no Brasil. Não é incomum que Martins Pena seja visto apenas de passagem no contexto da história da literatura brasileira, muitas vezes sendo mal compreendido, mesmo na posição de comediógrafo e homem de teatro. No entanto, suas mensagens continuam vivas e seus textos ainda têm muito o que revelar ao público.

\section{Referências}

ARÊAS, Vilma Sant'Anna. Na tapera de Santa Cruz. São Paulo: Martins Fontes, 1987.

CONDÉ, José. Entrevista com Darcy Damasceno. "Escritores e Livros". Correio da Manhã, 14 jan. 1959.

CORREIO OFFICIAL. Rio de Janeiro: Tipografia Nacional, de 1835 a 1841.

DAMASCENO, Darcy. De Gregório a Cecília. SECCHIN, Antonio Carlos; DAMASCENO, Iracilda (Orgs.). Rio de Janeiro: Galo Branco, 2007.

DIÁRIO DO RIO DE JANEIRO. Rio de Janeiro: Tip. do Diário, N. L. Vianna, fev. 1836.

JORNAL DO COMMERCIO. Rio de Janeiro, fev. 1839. 
MAGALHÃES JÚNIOR, Raimundo. Martins Pena e sua época. 2 ed. São Paulo: Lisa, 1972.

MARTINS PENA. O juiz de paz da roça e O Judas no Sábado de Aleluia. COSTA, Amália (Org.). Rio de Janeiro: Organização Simões, 1951.

MARTINS PENA. Comédias. Darcy Damasceno (Org.). Rio de Janeiro: MEC/INL, 1956.

MARTINS PENA. Folhetins. Rio de Janeiro: MEC/INL, 1965.

O CHRONISTA. Rio de Janeiro: Tip. de J. do N. Silva, 13 mar. 1838.

O DESPERTADOR. Rio de Janeiro, 1ํㅡ mar. 1839.

SILVA, João Manuel Pereira da. Literatura grega e romana. Nitheroy, revista brasiliense: ciências, letras e artes. Paris, 1836, v. 2, p. 219-43.

VEIGA, Luiz Francisco da. Martins Penna: o criador da comédia nacional. Revista do IHGB. Rio de Janeiro: Garnier, 1877. Tomo XL, II.

Recebido em: 14/07/2014

Aprovado em: 14/09/2014 